\title{
The Relationship Between Photosynthesis Daily Changes and The Bulb Quality of Five Cultivars of Garlic
}

\author{
Jiaying Wu${ }^{1}$, Wen Wan ${ }^{1}$, Junjuan Wang1, Yuzhong Gao ${ }^{2}$, Jingjing Shi ${ }^{2}$, Yiren Su${ }^{1}$, Chunyan $\mathrm{Xu}^{1}, \mathrm{Jie}^{1}{ }^{1}$, \\ Jihong Jiang ${ }^{1}$, Xuqin Yang ${ }^{*}$
}

\author{
${ }^{1}$ The Key Laboratory of Biotechnology for Medicinal Plant of Jiangsu Province, School of Life Science, \\ Jiangsu Normal University, Xuzhou 221116, Jiangsu, China \\ ${ }^{2}$ Xuzhou Nuote Chemical co., Ltd., Xuzhou 221137, Jiangsu, China \\ *Correspondence Author
}

\begin{abstract}
All organisms obtain energy and substances through photosynthesis directly or indirectly. This study order to explore the relationship between the photosynthesis daily changes and bulb quality of different cultivars of garlic. Tianshui garlic (TS), Pizhou purple garlic (PZ), Wenzhou small bulb (WX), Henan Nanyang 1 garlic (HN1), Henan Luohe Garlic (HL) were used as the test material. Use field experiments. With the help of CI-340 portable photosynthesis tester and vernier caliper, the photosynthesis-related parameters and bulb (Weight/g, Transverse diameter/cm, Longitudinal diameter/cm) trait data of various cultivars of garlic were measured. The results showed that the daily changes of the net photosynthetic rate and transpiration rate of the five kinds of garlic showed an irregular double-peak curve, the photosynthetic active radiation and leaf temperature all formed a single-peak curve, and the daily changes of the net photosynthetic rate and transpiration rate showed Obvious positive correlation trend, the changing trend of intercellular $\mathrm{CO}_{2}$ concentration is opposite to the changing trend of net photosynthetic rate. All five kinds of garlic have the phenomenon of "photosynthetic lunch break", and the phenomenon of PZ "photosynthetic lunch break" is the most obvious. Each specie's net photosynthetic rate of species in the morning was higher than the net photosynthetic rate in the afternoon. PZ performed well in parameters such as net photosynthesis rate and transpiration rate, and garlic bulb quality was the highest. WX has low water use efficiency and relatively good garlic varieties, indicating that WX has good waterlogging tolerance and can be used as a breeding resource for labour resistance. This study provides a good research foundation for further revealing the garlic photosynthesis mechanism and the analysis of bulb quality.
\end{abstract}

Keywords: Garlic, Photosynthesis, Net photosynthetic rate, Bulb quality.

\section{Introduction}

Garlic (Allium sativum L., Liliaceae), $(2 \mathrm{n}=2 \mathrm{X}=16)$, has been widely cultivated for over 5000 years[1-3]. In China, the garlic of planting area and output rank first in the world, and the output accounts for about $4 / 5$ of the world's total output[4]. Garlic is given the laudatory name of "plant gold" because of its important medicinal value and economic value[5]. Studies have shown that garlic has significant efficacy in antioxidant[6], stable blood pressure[7], cancer prevention[8] and cardiovascular protection[9], as well as sterilization and anti-inflammatory[10]. Garlic is mainly composed of bulb, leaf, root and garlic ballads and has important agronomic characters. Among them, the garlic bulb is the most important economic product at present. Garlic bulb is rich in carbohydrates, protein, fat, niacin, organic sulfide[11] and polyfructose[12]. At the same time, Chinese Pharmacopoeia[13] also regards the bulb as one of the important indicators to measure the good quality of garlic.

The plants of growth and development cannot be separated from the photosynthesis of plants[14], which provides necessary organic matter for plants through the transformation of matter and energy[15]. In recent years, the relationship between the diurnal variation of photosynthesis and agronomic traits has been studied in crops[16], garden plants[17] and fruit trees[18]. Xue[19] studied the effects of different concentrations of fertilizer on photosynthesis, yield and quality of eggplants. Allah[20] studied that applying $2 \% \mathrm{k}$ fertilizer to corn leaves under drought conditions improved stomatal conductance, photosynthetic rate and chlorophyll content shape of corn leaves, which affected grain size and weight. Zhang[21] studied that different chemical fertilizer combinations can significantly promote the photosynthetic rate of potato plants and thus improve potato tuber yield. However, there are few reports on the relationship between photosynthesis and the yield of garlic. China has a wide area and a rich and diverse ecological environment. Through a long biological evolution, garlic has gradually formed local varieties of different ecological types, and there are certain differences. Five garlic representatives-TS, PZ, WX, HN1 and HL were selected as materials according to spatial difference, regional span, market circulation and other factors. The CI-340 portable photosynthesis apparatus was developed for the determination of the different varieties of garlic leaf net photosynthetic rate, transpiration rate, intercellular $\mathrm{CO}_{2}$ concentration, water use efficiency, photosynthetic active radiation, leaf temperature differences, combined with the weight of the garlic bulbs longitudinal diameter, transverse diameter and explore in the mature period the changing trend of photosynthetic capacity and garlic bulb quality of the relationship. This study provided a potential scientific basis for understanding the ecological adaptation mechanism of different varieties of garlic to light environments and promoting the development of garlic quality varieties.

\section{Materials and Methods}

\subsection{Materials and Plant Conditions}

The plant materials selected-TS, PZ, HN1, WX, HL were all sampled in various regions to ensure the accuracy of material 
germplasm. Garlic planting in ChaoHu Village, Tongshan District, Xuzhou City, Jiangsu Province, vegetable field base, spacing $30 \mathrm{~cm}$, row spacing $30 \mathrm{~cm}$. The basic physical and chemical properties of the field soil were as follows: $\mathrm{pH} 6.54$, organic matter $8.8 \mathrm{~g} / \mathrm{kg}$, total nitrogen $0.82 \mathrm{~g} / \mathrm{kg}$, available phosphorus $3.2 \mathrm{mg} / \mathrm{kg}$ and available potassium $106.9 \mathrm{mg} / \mathrm{kg}$.

\subsection{Determination of Photosynthesis Related Parameters}

Using CI-340 portable photosynthetic apparatus (USA), from 08:00 to 18:00 Beijing time, three garlic leaves of five varieties were randomly selected for determination, determination every $90 \mathrm{~min}$, determination of daily changes in photosynthesis for three consecutive days, and then the average value was obtained for data processing. The indexes included net photosynthetic rate $(\mathrm{Pn})$, transpiration rate $(\mathrm{E})$, intercellular $\mathrm{CO}_{2}$ concentration $\left(\mathrm{InTCO}_{2}\right)$, water use efficiency $(\mathrm{H})$, photosynthetically active radiation (PAR) and leaf surface temperature (Tleaf). Water use efficiency $(\mathrm{H})$ was calculated by $\mathrm{H}=\mathrm{Pn} / \mathrm{E}$.

\subsection{Determination of Garlic Bulb Character Parameters}

$\mathrm{Lu}[22]$ conducted correlation analysis on the agronomic traits and yield of garlic, and the results showed that the cross diameter, longitudinal diameter and weight of garlic bulbs were the main agronomic traits affecting bulb yield per plant. Therefore, we used vernier callipers (Japan Santoyo brand) and electronic balance (Shanghai Shunyu Hengping FA224 electronic analytical balance) to measure the weight $/ \mathrm{g}$, transverse diameter and longitudinal diameter / $\mathrm{cm}$ of garlic bulbs of various varieties.

\subsection{Statistical Analysis}
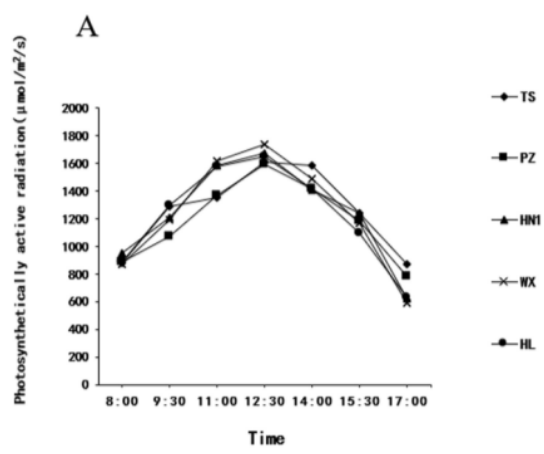

Microsoft Excel worksheet was used for data processing and analysis.

\section{Result}

\subsection{The Difference of Garlic Photosynthetic Active Radiation and Foliar Temperature}

The amount of energy that plants use to absorb solar radiation during photosynthesis is called photosynthetically active radiation (PAR). Photosynthetically active radiation is the basic energy to biomass, which directly affects plant growth and development, yield and product quality. As can be seen from Fig1B, the peak value of photosynthate of 5 garlic varieties appeared at about 12:30 in a day, presenting a "single-peak" curve. Among the five cultivars, WX had the highest peak value of photosynthetically active radiation, which was $1737.83 \mu \mathrm{mol} \cdot \mathrm{m}^{-2} \cdot \mathrm{s}^{-1}$. PZ had the lowest peak value of photosynthetically active radiation (PZ), which was $1597.20 \mu \mathrm{mol} \cdot \mathrm{m}^{-2} \cdot \mathrm{s}^{-1}$. The peak value of photosynthetically active radiation is $\mathrm{PZ}, \mathrm{TS}, \mathrm{HL}, \mathrm{HN} 1$ and $\mathrm{WX}$ from small to large. Among the five varieties, the minimum value of photosynthetic active radiation (PSR) appeared at about 17:00, especially that of WX $\left(590.30 \mu \mathrm{molm} \mathrm{m}^{-2} \cdot \mathrm{s}^{-1}\right)$, and that of TS $\left(869.60 \mu \mathrm{mol} \cdot \mathrm{m}^{-2} \cdot \mathrm{s}^{-1}\right)$. In addition, photosynthetic active radiation of 5 varieties decreased rapidly from 15:30 to 17:00.

The growth of plants is greatly affected by temperature. Plant leaves have many functions, so leaf temperature can be used as an important indicator of plant physiological sensing. According to Fig1A, the leaf temperature of 5 garlic varieties showed A "single-peak" curve, and the peak value of leaf temperature of 5 garlic varieties all appeared at about 14:00, and the peak value ranged from $33^{\circ} \mathrm{C}$ to $34^{\circ} \mathrm{C}$.

B

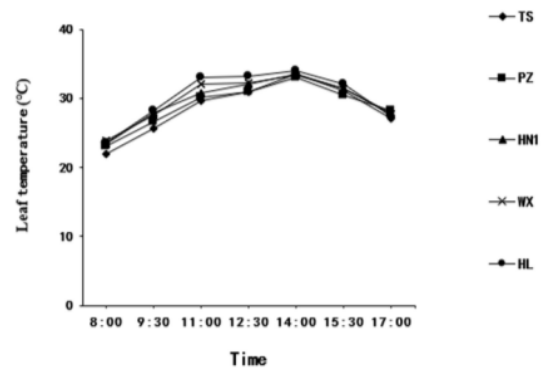

Figure 1: A: Five garlic varieties of photosynthetic active radiation (PAR) B: Five garlic varieties of leaf temperature (Tleaf)

\subsection{The Different Garlic Diurnal Variation of Net Photosynthetic and Transpiration Rate}

The net photosynthetic rate of plants is a basic factor to measure the photosynthetic productivity of plant leaves[23]. The diurnal variation of plant photosynthesis is the basis of physiological metabolism and substance accumulation in plant production, and is also an important means to analyze the impact of environmental factors on plant growth and metabolism[24]. Under general conditions, the diurnal variation of photosynthesis of cultivated plants is regular, and its variation curve is bimodal or unimodal. As shown in Fig $2 \mathrm{~B}$, the variation curves of the net photosynthetic rate of 5 garlic varieties all showed a "bimodal" curve. The net photosynthetic rate reached the first peak at 9:30 and then decreased, bottomed out at about 12:30, then rose briefly, reached the second peak at about 14:00, and then decreased again. The first peak value of the net photosynthetic rate of 5 garlic cultivars was greater than the second peak value. The diurnal variation curve of net photosynthetic rate of PZ was significantly better, and the first peak value of net photosynthetic rate was $90.80 \mu \mathrm{mol} \cdot \mathrm{m}^{-2} \cdot \mathrm{s}^{-1}$, and the second peak value was $70.80 \mu \mathrm{mol} \cdot \mathrm{m}^{-2} \cdot \mathrm{s}^{-1}$. The diurnal variation curve of NET photosynthetic rate of TS was obviously poor. The first peak value of net photosynthetic rate was $79.06 \mu \mathrm{mol} \cdot \mathrm{m}^{-2} \cdot \mathrm{s}^{-1}$, and the second peak value was $65.06 \mu \mathrm{mol} \cdot \mathrm{m}^{-2} \cdot \mathrm{s}^{-1}$. Based on the analysis and comparison of Fig1A and Fig2B, 5 garlic varieties all showed obvious photosynthetic "nap" phenomenon, among which PZ showed the most obvious photosynthetic "nap" phenomenon. 
Transpiration of plant leaves is an important way to keep the temperature of plant leaves, and transpiration is related to stomatal closure. Transpiration affects the photosynthetic process of plants by affecting stomatal closure[25]. According to Figure $2 \mathrm{~A}$, the diurnal variation of transpiration rate of 5 garlic varieties was obvious, and presented an obvious "bimodal" curve, reaching the first peak at about 11: 00, then

A
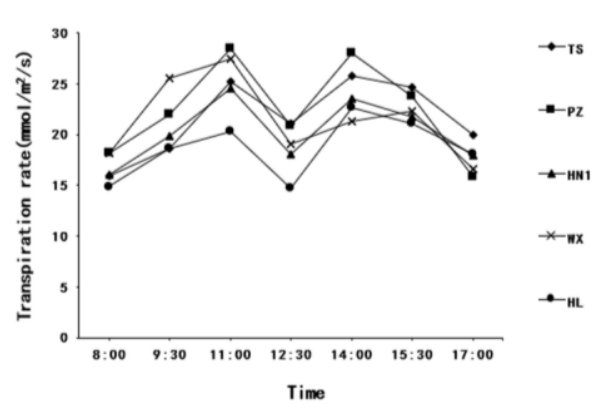

sharply decreasing, reaching A trough at about 12: 30 , then sharply increasing, reaching the second peak at about 14: 00 and then decreasing successively. The first peak value of PZ appeared at around 11: 00, 28.50mmol $\cdot \mathrm{m}^{-2} \cdot \mathrm{s}^{-1}$, and the second peak value appeared at around 15: $30,28.02 \mathrm{mmol} \cdot \mathrm{m}^{-2} \cdot \mathrm{s}^{-1} . \mathrm{In}$ general, the diurnal variation trend of transpiration rate was similar to that of net photosynthetic rate.

B

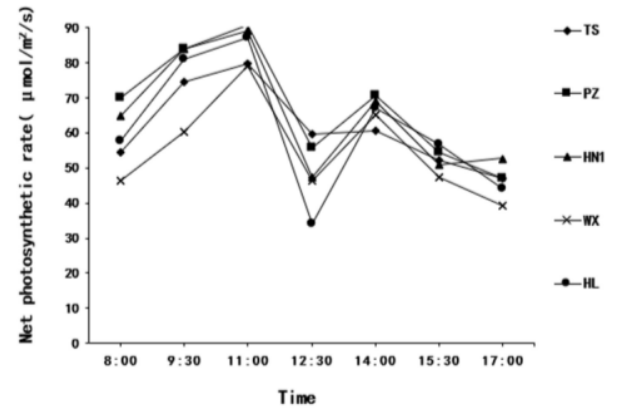

Figure 2: A: Five garlic varieties of daily changes of transpiration rate(E) B: Five garlic varieties of daily changes of net photosynthetic rate $(\mathrm{Pn})$

\subsection{The Different Garlic Diurnal Variation of Water Use Efficiency and Intercellular $\mathrm{CO}_{2}$ Concentration}

Figure 3 A shows that the peak pattern of water use efficiency curves of TS and PZ is not obvious. The water use efficiency of HN1, HL and WX were all bimodal curves, with the first peak at about 9:00. The peak value of HN1 was $4.22 \mu \mathrm{mol} \cdot \mathrm{mmol}^{-1}$, and the peak value of $\mathrm{HL}$ was $4.34 \mu \mathrm{mol} \cdot \mathrm{mmol}^{-1}$, and then the curve continued to decline. The second peak value of HN1 was $2.93 \mu \mathrm{mol} \cdot \mathrm{mmol}^{-1}$ at about 14:00, and the second peak value of $\mathrm{HL}$ was $2.96 \mu \mathrm{mol} \cdot \mathrm{mmol}^{-1}$ at about 15:30. During the whole process, THE water use efficiency of HL kept a high level. The first peak value of WX

A

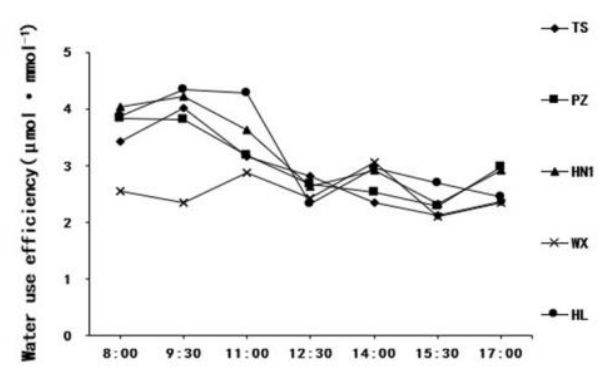

was $2.88 \mu \mathrm{mol} \cdot \mathrm{mmol}^{-1}$ at around 11:00, and the second peak value was $3.06 \mu \mathrm{mol} \cdot \mathrm{mmol}^{-1}$ at $14: 00$.

As can be seen from Figure $3 \mathrm{~B}$, the variation trend of intercellular $\mathrm{CO}_{2}$ concentration of different garlic varieties was "W" type, reaching the lowest value at 11:00 am and then increasing, and then decreasing after reaching the peak value at 12:30 am. The second trough value appeared at 15:30 PM and then rising sharply. The changing trend of intercellular $\mathrm{CO}_{2}$ concentration was basically opposite to net photosynthetic rate. During the whole process, the intercellular $\mathrm{CO}_{2}$ concentration of $\mathrm{PZ}$ was kept at a high level, while that of TS was basically at a low level.

B

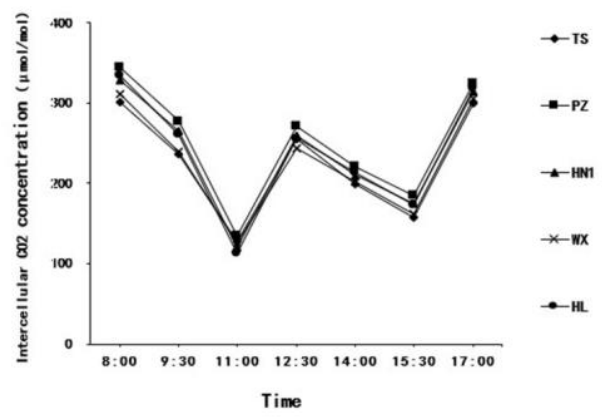

Figure 3: A: Five garlic varieties of diurnal variation of water use efficiency (WUE) B: Five garlic varieties of intercellular $\mathrm{CO}_{2}$ concentration $(\mathrm{Ci})$

\subsection{Measurement of Bulb Quality of Five Garlic Varieties}

In Table 1, the weight, cross diameter and longitudinal diameter of PZ garlic were significantly higher than other varieties. Compared with the other four varieties of garlic, TS garlic weight, cross diameter, vertical stem is the lowest, that is, the worst quality. According to quality $\mathrm{PZ}>>\mathrm{HN} 1>\mathrm{HL}>$ $\mathrm{WX}>\mathrm{TS}$.

Table 1: The bulb quality measurement of five garlic varieties

\begin{tabular}{|c|c|c|c|c|c|c|c|c|c|}
\hline Species & \multicolumn{3}{|c|}{ Weight $(\mathrm{g})$} & \multicolumn{3}{|c|}{ Transverse diameter(cm) } & \multicolumn{2}{|c|}{ Vertical diameter(cm) } \\
\hline HL & 61.47 & 63.55 & 65.78 & 5.20 & 5.35 & 3.52 & 3.66 & 3.64 & 3.71 \\
\hline HN1 & 57.56 & 54.69 & 59.38 & 4.87 & 4.71 & 5.04 & 3.49 & 3.41 & 3.57 \\
\hline TS & 34.64 & 32.37 & 35.95 & 3.69 & 3.84 & 4.01 & 2.56 & 2.44 & 2.65 \\
\hline PZ & 70.56 & 68.47 & 73.42 & 5.83 & 5.67 & 5.98 & 3.86 & 3.74 & 3.96 \\
\hline WX & 44.64 & 42.37 & 45.95 & 4.40 & 4.25 & 4.55 & 3.16 & 2.95 & 3.24 \\
\hline
\end{tabular}




\section{Results and discussion}

The diurnal variation of photosynthesis can reflect the physiological metabolism and organic matter accumulation capacity of plants in a day, which can help us to understand the light utilization capacity of different varieties of garlic and the relationship between their scale diameter and quality, so as to better apply in practical cultivation and analysis of garlic quality. As the photosynthetical active radiation reaches the maximum value at 12:00, the atmospheric temperature rises, the relative humidity of the air decreases, the transpiration and water loss of garlic leaves accelerates, and the leaf temperature rises. In order to maintain water, plants close part of stomata, so carbon dioxide absorption is blocked, and the net photosynthetic rate decreases. Therefore, photoinhibition and stomatal closure caused by strong light and water deficit are important reasons for the "nap" of plant photosynthesis[26]. In this paper, the results of analysis show that the five varieties of garlic of diurnal change of photosynthetic curve shows bimodal type curve, has evident photosynthetic "noon break" phenomenon, with the first peak around 9:00 in the morning, at noon 12:00 PM, there was a valley value 14:00 PM appear the second peak, and the transpiration rate of similar diurnal variation trend.

Plant transpiration is closely related to net photosynthetic rate. Wue is a comprehensive reflection of photosynthetic and transpiration characteristics of plants, and its size can reflect the strength of plants' ability to adapt to adversity[27]. According to the results of this study, garlic WX has relatively high net photosynthetic rate and transpiration rate, but low water use efficiency compared with other varieties, so it is suitable for planting in areas with high humidity and low terrain, and has strong waterlogging resistance. PZ not only had a good performance in transpiration rate, water use efficiency and other indicators, but also had a higher net photosynthetic rate than the other four varieties of garlic.

In the correlation analysis, the weight, transverse diameter and longitudinal diameter of garlic were positively correlated with quality, which could be used as an important reference index for high-quality breeding in the field. The net photosynthetic rate was PZ\&gt from high to low. $\mathrm{HN} 1>\mathrm{HL}>\mathrm{WX}>\mathrm{TS}$, this is the same thing as garlic. At the same time, it can be seen that good quality varieties, their photosynthetic rate and water use efficiency are relatively higher. We found that the quality of five kinds of garlic was positively correlated with the net photosynthetic rate and water use efficiency, indicating that the higher the photosynthetic rate and water use efficiency of garlic, the better the quality of garlic.

\section{Acknowledgments}

This work was financially supported by Jiangsu Normal University, Jiangsu Graduate Research Practice and Innovation Practice Project (KYCX20_2287), Xuzhou Science and technology project (KC20040), Jiangsu Jieqing Reserve Project (HB2016016), National Natural Science Foundation of China (31801720; 31672148), Jiangsu Provincial Advantage Discipline Construction Project (PAPD).

\section{References}

[1] Satyal P, Craft J D, Dosoky N S, et al. The Chemical Compositions of the Volatile Oils of Garlic (Allium sativum L.) and Wild Garlic (Allium vineale)[J]. Foods, 2017, 6(8): 62

[2] Xiaojun C, Xia L, Siyuan Z, et al. Transcriptomereferenced association study of clove shape traits in garlic[J]. DNA Research, 2018, 6(12): 588.

[3] Petropoulos S, Fernandes A, Barros L, et al. Antimicrobial and antioxidant properties of various Greek garlic genotypes[J]. Food Chemistry, 2018, 245: 7.

[4] Zhao L, Yang R, Yin Y, et al. The Application of the Intelligent Mechanical Arm in the Planting of Garlic[J]. Journal of Agricultural Mechanization Research, 2014, 2-9: 7.

[5] Augusto H, Eugenia L, Ri Ca, et al. Comparison and Characterization of Garlic (Allium sativum L.) Bulbs Extracts and Their Effect on Mortality and Repellency of Tetranychus urticae Koch (Acari: Tetranychidae)[J]. Chilean Journal of Agricultural Research, 2008, 68(4):320.

[6] Lu X, Li N, Qiao X, et al. Composition analysis and antioxidant properties of black garlic extract[J]. J Food Drug Anal. 2016, 25(2): 340.

[7] Ajamzibad H, Beydokhti T B, Mohtasham F, et al. Effects of boiled garlic and Shirazi lemon on blood lipids in hyperlipidemic patients: A quasi-experimental study[J]. Journal of Herbal Medicine, 2021, 12 (2): 100439.

[8] Lv Y, So KF, Wong NK, et al. Anti-cancer activities of Sallyl-mercapto-cysteine from aged garlic[J]. Chin J Nat Med. 2019, 17(1): 43.

[9] Varshney R, Budoff MJ. Garlic and heart disease[J]. J Nutr. 2016, 13(1): 417.

[10] Hsieh C C, Liu K F, Liu P C, et al. Comparing the Protection Imparted by Different Fraction Extracts of Garlic (Allium sativum L.) against Derp-Induced Allergic Airway Inflammation in Mice[J]. International Journal of Molecular Sciences, 2019, 20(19): 4879.

[11] Rodrigues C, Percival S. Immunomodulatory Effects of Glutathione, Garlic Derivatives, and Hydrogen Sulfide[J]. Nutrients, 2019, 11(2): 64.

[12] Maa B, Tms A, Hm A, et al. Antimicrobial garlic-derived diallyl polysulfanes: Interactions with biological thiols in Bacillus subtilis $[\mathrm{J}]$. Biochimica et Biophysica Acta (BBA)-General Subjects, 2019, 1863(6): 1054

[13] Zhao D S, Li X X, Guan M, et al. Study on the discussion about quality specification of garlic[J]. Chinese Journal of Pharmaceutical Analysis, 2012, 32(3): 498.

[14] Di Q, Li J, Du Y, et al. Combination of Red and Blue Lights Improved the Growth and Development of Eggplant (Solanum melongena L.) Seedlings by Regulating Photosynthesis[J]. Journal of Plant Growth Regulation, 2020, 17(8): 8.

[15] Ryszka P, Lichtscheidl I, Tylko G, et al. Symbiotic microbes of Saxifraga stellaris SSP. alpigena from the copper creek of Schwarzwand (Austrian Alps) enhance plant tolerance to copper[J]. Chemosphere, 2019, 228(8): 187. 
[16] Li S, Fleisher D H, Wang Z, et al. Application of a coupled model of photosynthesis, stomatal conductance and transpiration for rice leaves and canopy[J]. Computers and Electronics in Agriculture, 2021, 182(3): 106047.

[17] Sukhova E M, Vodeneev V A, Sukhov V S. Mathematical Modeling of Photosynthesis and Analysis of Plant Productivity[J]. Biochemistry Supplement Series A Membrane and Cell Biology, 2021, 15(1): 59.

[18] Rosati A, Wolz K J, Murphy L, et al. Modeling light below tree canopies overestimates net photosynthesis and radiation use efficiency in understory crops by averaging light in space and time $[\mathrm{J}]$. Agricultural and Forest Meteorology, 2020, 284: 107892

[19] Xue J, Xie J M, Xiao X M, et al. Effects of different slow-release fertilizers on growth, yield and quality of eggplants[J]. Acta Agriculturae Zhejiangensis, 2015, 18 (3), 4

[20] Wasaya A, Yasir T A, Sarwar N, et al. Foliage applied potassium improves stay green, photosynthesis and yield of maize (Zea mays L.) under rainfed condition[J]. Plant Physiology Reports, 2021, 26(2).

[21] Zhang J, Yang W, Zhou Z. Fenoxaprop combined with urea improves photosynthesis, weed control, and yield of potato[J]. Crop Science, 2021: 23(5),61.

[22] Xin-Juan L U, Yang F, Fan J D, et al. Correlation and Path Analysis of Main Agronomic Characters of Garlic (Allium sativum L.)[J]. Acta Agriculturae Jiangxi, 2010, 17(5): 89-98, 90.

[23] Sun S B, Du H Q, Li P H, et al. Retrieval of leaf net photosynthetic rate of moso bamboo forests using hyperspectral remote sensing based on wavelet transform[J]. Chinese Journal of Applied Ecology, 2016, 27(1): 49-58, 50.

[24] Feng J, Zhang Y. Studies on the diurnal changes of net photosynthesis rate and the effect of environmental factors of camptotheca acuminata[J]. Scientia Silvae Sinicae, 38(4), 34-39, 35.

[25] Peng Z, Duan A, Liu Z, et al. Research on Plant Transpiration in Eggplant in Solar-heated Greenhouse[J]. Irrigation \& Drainage, 2002, 14(7): 89-98, 90.

[26] Tezara W, Mitchell V J, Driscoll S D, et al. Water stress inhibits plant photosynthesis by decreasing coupling factor and ATP[J]. Nature, 1999, 401(6756): 914-917. 915.

[27] Jiang X, Zhang X, Xie T. Study on Photosynthetic Characteristics and Water Use Efficiency at Seedling Stage of Sassafras tsumu Hems1[J]. Guizhou Forestry ence and Technology, 2016, 18 (3), 4.

\section{Author Profile}

Jiaying Wu, Suqian, Jiangsu Province, full-time graduate student, mainly engaged in garlic related research.

Xuqin Yang, Corresponding author, $\mathrm{PhD}$, associate professor, mainly engaged in garlic biotechnology research. 